\title{
ANNULAR PANCREAS WITH DUODENAL STENOSIS AND INTESTINAL MALROTATION IN TWO YEARS GIRL - CASE REPORT
}

\author{
Edin HUSARIĆ, Nešad HOTIĆ, Amir HALILBASIĆ, Emir RAHMANOVIĆ, Sanimir SULJENDIĆ
}

Department of Paediatrics University Clinical Hospital Tuzla

Tuzla, Bosnia and Herzegovina

Corresponding author:

Edin Husaric

Department of Paediatrics Surgery

University Clinical Hospital Tuzla

Trnovac bb, 75 000, Tuzla

Bosnia and Herzegovina

ehusaric@hotmail.com

Tel.: + 38735303369

Fax.: + 38735303730

Received: November 2, 2013

Accepted: December 30, 2013

Copyright (C) 2014 by University Clinical Hospital Tuzla. E-mail for permission to publish:paediatricstoday@ukctuzla.ba

\begin{abstract}
Objective - To describe a rare case of a combination of annular pancreas with malrotation in early childhood. Case report - The patient is 2 year old aged girl with persistent non-bilious vomiting. She was vomiting several times a week, and over the ten days prior to presentation as many as several times a day. Upon presentation, the patient had an unremarkable abdominal exam with no abdominal pain. An upper gastrointestinal study showed extreme dilatation of the stomach and the duodenal bulb, and an abdominal computer tomography scan revealed an annular pancreas. Intra-operatively we find an annular pancreas and treated it by duodeno-duodenostomy, while the intestinal malrotation was treated by Ladd's procedure. Conclusion - Annular pancreas is a rare congenital anomaly which in childhood is related to duodenal atresia or stenosis and often affiliated with intestinal malrotation.
\end{abstract}

Key words: Annular pancreas - Malrotation.

\section{Introduction}

Annular pancreas (AP) is a rare congenital anomaly characterized by the presence of pancreatic tissue of variable width, completely or partially obstructing the second part of the duodenum. It forms due to the failure of normal migration of the ventral pancreatic bud, which results in some of the pancreatic tissue encircling the duodenum (1). It is estimated that it occurs in one of every 12,000-15,000 live births (2). The incidence of annular pancreas has been reported to be $0.005 \%-0.015 \%$ in autopsy cases in adults. It is frequently associated with other congenital abnormalities, such as: oesophageal atresia, imperforate anus, congenital heart dis- ease, malrotation of the midgut, and Down's syndrome (3). In contrast to adults, children with $\mathrm{AP}$ always present with signs and symptoms of gastrointestinal obstruction and AP in children is frequently associated with other congenital anomalies (4). Only 737 cases have been reported in the English literature to date, with a slight female preponderance. The majority of the reported cases have been reported in the newborn population. In newborns the main mode of presentation is that of duodenal obstruction (1).

We report a rare case of a combination of annular pancreas with malrotation in a two year old girl. 


\section{Case report}

We reported the case of 2 year old girl, weighing $10 \mathrm{~kg}$, with persistent non-bilious vomiting, present since the girl was three months old. She was vomiting several times a week, and over the ten days prior to presentation as many as several times a day. She vomited more often after eating solids. The girls was from a Roma family and did not have health insurance. That is why the parents did not take her to a physician earlier. On presentation, the patient had an unremarkable abdominal exam with no abdominal pain. An

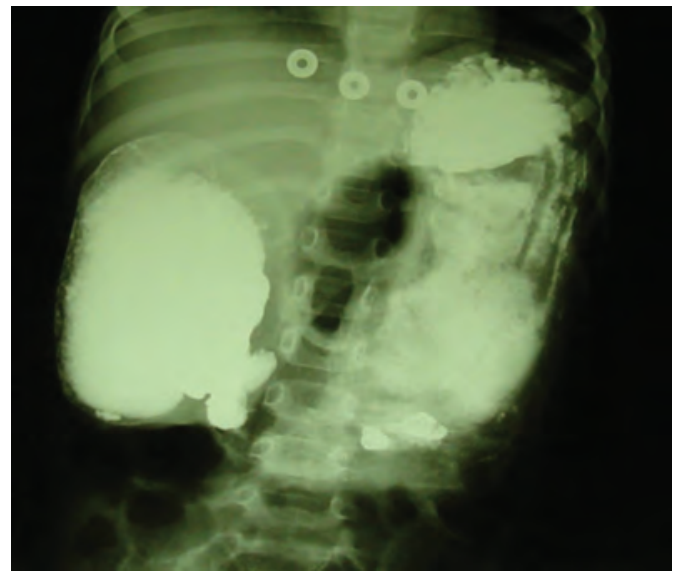

Fig. 1 Preoperative upper gastrointestinal series demonstrating extreme gastric and first part duodenal dilatation.

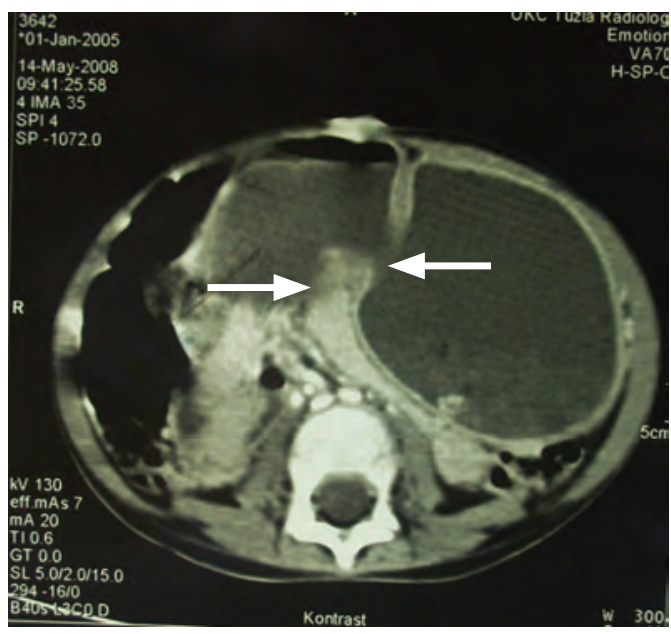

Fig. 2 Abdominal computer tomography scan. upper gastrointestinal image (UGI) demonstrated duodenal stenosis with extreme gastric and duodenal bulb dilatation (Fig. 1).

After that, we performed an abdominal computer tomography scan which raised the suspicion of annular pancreas (Fig. 2).

Based on the radiography findings, exploratory laparotomy was performed, which revealed a markedly distended stomach and proximal duodenum. Following mobilization of the duodenum, an annular pancreas, with complete duodenal obstruction, was found. Distally, the small bowel was normal. The annular pancreas was treated by Kimura's diamond-shaped-duodenoduodenostomy and the intestinal malrotation using Ladd's procedure (Fig. 3).

On the tenth postoperative day we performed a control UGI to show the proper passage of barium through the stomach and small intestine (Fig. 4).

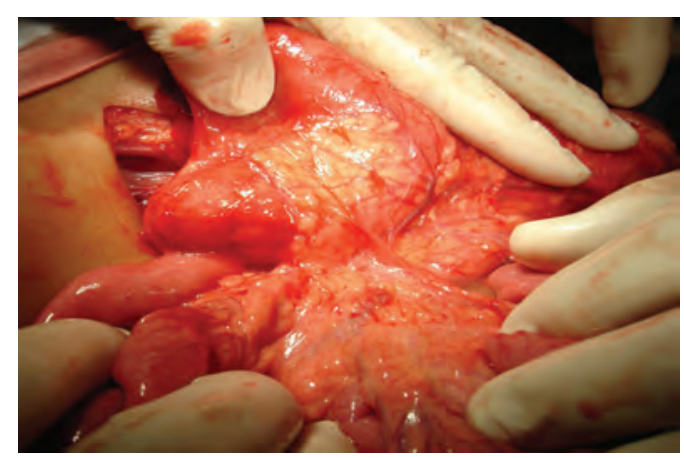

Fig. 3 Operative photograph showing the complete ring of pancreatic tissue encircling the second part of duodenum.

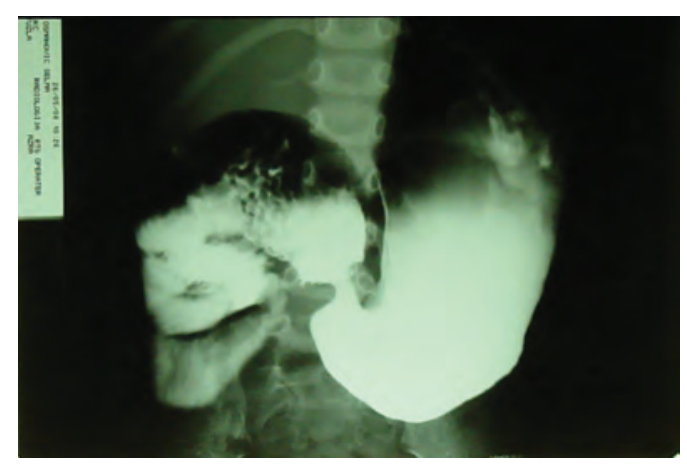

Fig. 4 Postoperative upper gastrointestinal series. 
The post-operative period was uneventful and the patient was discharged on the $12^{\text {th }}$ post-operative day.

\section{Discussion}

Annular pancreas, as first described by Tiedemann in 1818, is a rare congenital abnormality that accounts for $1 \%$ of all intestinal obstructions in the paediatric population (5). Two main theories regarding the formation of annular pancreas have been proposed. One is that the left ventral anlage persists and that the right ventral anlage does not rotate around the duodenum. The other theory is that the right ventral anlage stretches and encircles the duodenum (3). In the neonatal period, annular pancreas with duodenal obstruction is characterized by intractable vomiting. Plain abdominal radiography and upper gastrointestinal contrast-enhanced radiography will confirm duodenal obstruction. Diagnosis of annular pancreas is made on the basis of one of the imaging modalities, namely, sonography and computed tomography, or by endoscopic retrograde cholangiopancreatography (6). The first surgical treatment for an obstructive annular pancreas was performed by Vidal in 1905 (1). Annuli most commonly affect the descending duodenum and may be partially or completely circumferential. Complete duodenal obstruction typically occurs below the level of the ampulla of Vater and presents as bilious vomiting that worsens with subsequent feeding. A partially circumferential presentation may occur later in life, or it may be asymptomatic (3). The most common abdominal radiographic finding is the double-bubble sign, composed of gaseous dilatation of the stomach and proximal duodenum, with a paucity of bowel gas distally. The double-bubble sign may also be observed on prenatal ultrasound as 2 adjacent fluid-filled structures in the fetal upper abdomen, and may be accompanied by polyhydramnios. Differential diagnosis of this sign, detected either prenatally or postnatally, includes duodenal atresia, annular pancreas, duodenal stenosis, duodenal webs, and midgut volvulus (2). Annular pancreas is a recognized cause of duodenal obstruction in children (7), and may predispose to localized relapsing acute pancreatitis even in a child (8). Pancreatitis, in the setting of annular pancreas, may be associated with co-existing pancreaticobiliary malformations including pancreas divisum, pancreaticobiliary maljunction, choledochocele, or intraduodenal diverticulum (9). Surgical correction of annular pancreas has a good prognosis. Duodenoduodenostomy is recommended as it facilitates drainage of the pancreatic secretions through the duodenum, prevents future reflux by decreasing the intraluminal pressure, and relieves the gastrointestinal obstruction (10).

\section{Conclusion}

We have presented a case of a rare congenital developmental abnormality of the pancreas combined with intestinal malrotation. Duodenoduodenostomy is the appropriate treatment for annular pancreas and Ladd's procedure for malrotation. Prognosis is excellent, despite the frequent association with other anomalies such as, in our case, malrotation.

Authors' contributions: Conception and design: EH, $\mathrm{NH}$; Acquisition, analysis and interpretation of data: AH, ER; Drafting the article: SS; Revising it critically for important intellectual content: HT.

Conflict of interest: The authors declare that they have no conflict of interest.

\section{References}

1. Wani AA, Maqsood S, Lala P, Wani S. Annular pancreas in adults: a report of two cases and review of literature. JOP. 2013;14(3):277-9.

2. Lainakis N, Antypas S, Panagidis A, Alexandrou I, Kambouri K, Kyriazis C, et al. Annular pancreas 
in two consecutive siblings: an extremely rare case. Eur J Pediatr Surg. 2005;15(5):364-8.

3. Tadokoro H, Takase M, Nobukawa B. Development and congenital anomalies of the pancreas. Anat Res Int. 2011;2011:351217. doi: 10.1155/2011/351217. Epub 2011 May 14. PubMed PMID: 22567291.

4. Zyromski NJ, Sandoval JA, Pitt HA, Ladd AP, Fogel EL, Mattar WE, et al. Annular pancreas: dramatic differences between children and adults. J Am Coll Surg. 2008;206(5):1019-25.

5. Norton KI, Tenreiro R, Rabinowitz JG. Sonographic demonstration of annular pancreas and a distal duodenal diaphragm in a newborn. Pediatr Radiol. 1992;22(1):66-7.

6. Vijayaraghavan SB. Sonography of pancreatic ductal anatomic characteristics in annular pancreas. J Ultrasound Med. 2002;21(11):1315-8.
7. Jimenez JC, Emil S, Podnos Y, Nguyen N. Annular pancreas in children: a recent decade's experience. J Pediatr Surg. 2004;39(11):1654-7.

8. Ohno Y, Kanematsu T. Annular pancreas causing localized recurrent pancreatitis in a child: report of a case. Surg Today. 2008;38(11):1052-5.

9. Urushihara N, Fukumoto K, Fukuzawa H, Suzuki K, Matsuoka T, Kawashima S, et al. Recurrent pancreatitis caused by pancreatobiliary anomalies in children with annular pancreas. J Pediatr Surg. 2010;45(4):741-6.

10. Komuro H, Gotoh C, Urita Y, Fujishiro J, Shinkai T. A pediatric case of an unusual type of annular pancreas presenting with duodenopancreatic reflux. Pediatr Surg Int. 2012;28(7):715-7. 